\section{PIERRE LASJAUNIAS}

D ierre Lasjaunias died suddenly on July 1, 2008, between meetings of the Executive Committee of the European Society of Neuroradiology in Freiburg, Germany, and of the Interventional Neuroradiology Course in Zurich, Switzerland. The abrupt news spread worldwide within hours and plunged the neuroradiology community into stupor and disarray, which could only be explained by the loss of an exceptional individual.

Pierre Lasjaunias was born July 15, 1948, in Paris. He attended medical school in Paris between 1968 and 1975 while rising through the ranks of the anatomy laboratory, where he held the positions of monitor, assistant, and head of research. Named a specialist in radiology in 1983, he was one of the first to successfully link radiology and anatomy, disciplines in which he excelled as a teacher. In 1989, he was named Professor. Even as a student, he was passionate about the nervous system, choosing to study vascular neuroradiology under Dr. Jacqueline Vignaud, who was director of the Radiology Department at the Fondation Rothschild in Paris.

Although younger than many of his colleagues, Pierre rapidly gained recognition from members of the young specialty of interventional neuroradiology and participated in the first reunion of an international think tank which, in 1980, brought together 14 of the best specialists in Santa Barbara, Calif. This group, named the "Working Group in Interventional Neuroradiology," still exists and now holds its yearly meeting at Val d'Isère in France. Pierre was an untiring and active participant at these meetings, and in 1991, at Bicêtre Hospital, he started a teaching seminar called "Anatomy, Biology, and Clinical Correlations," which, in 1996, became integrated with the meeting in Val d'Isère. Thus ABC/WIN was born, bringing together an increasing number of physicians and scientists who are interested in a global approach to the diseases they treat. In 1999, he created, along with the Universities of Paris-Sud and Mahidol in Bangkok, an International Diploma in Neurovascular Diseases so that physicians of the Asian Pacific Rim would have the opportunity to receive a unique education. The success of this program was great, and soon it attracted doctors from around the world.

He had directed the vascular neuroradiology section at Bicêtre Hospital since 1987 and was named Head of the Neuroradiology Department in 1998. Well aware that diagnostic and interventional neuroradiology cannot exist in a vacuum, Pierre believed that the only solution was that neuroradiology should be part of the general neurosciences. This led him to become Director of the Head and Neck Division of Bicêtre Hospital in 2007.

Pierre Lasjaunias quickly recruited patients from all over the world, who were drawn to Bicêtre by his outstanding professional and human qualities. Progressively, he acquired a unique expertise in the treatment of certain rare pathologies, such as aneurysms of the vein of Galen and pediatric spinal arteriovenous malformations. Surrounded by his loyal collaborators, Georges Rodesch and Hortensia Alvarez, he created a veritable international academy, with the distinction of his being named Visiting Professor in London, Berlin, New York, and Toronto. In 1998, he received an honorary membership

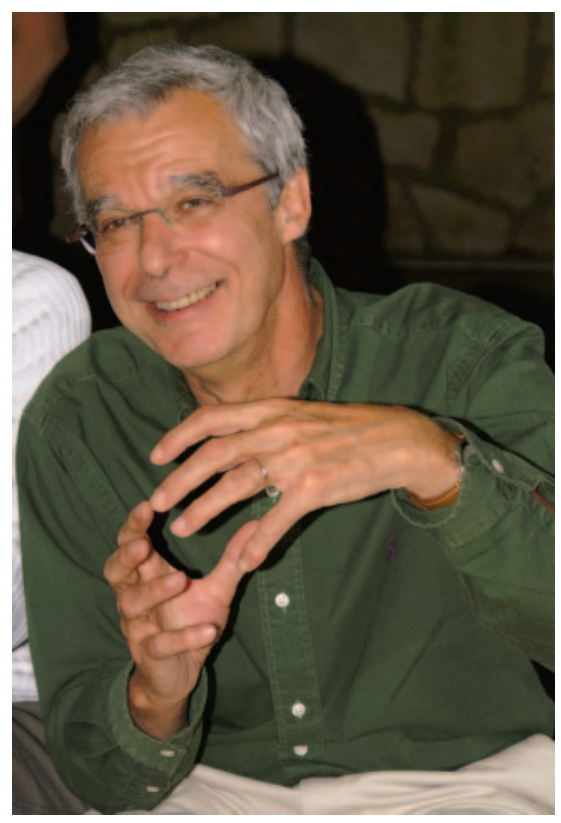

from the American Society of Neuroradiology. Having been a pilot, Pierre integrated the rigorous methods used in aviation to ensure patient safety. This idea would soon be embraced in France, where in surgery the use of a "checklist" is now required in certain procedures.

If Pierre Lasjaunias was capable of forging such a road, it was because he possessed many qualities rarely found in a single individual. Throughout his life, he never ceased to contemplate and build on ideas, elaborating new concepts based on his remarkable knowledge of embryology and anatomy, challenging other specialists to follow, always demonstrating a rare and creative activity. One of his last articles, entitled "Cerebral Proliferative Angiopathy," appeared in Stroke. This original work was the fruit of careful analysis and numerous discussions with colleagues, which allowed him to identify a new entity different from other brain arteriovenous malformations. He did not wish to keep his immense knowledge for his personal use, and that desire led him to publish several books in collaboration with his friends Alex Berenstein and Karel TerBrugge. These books now serve as a reference in the field and are considered by many as "bibles." In 1995, he started the journal Interventional Neuroradiology in collaboration with Marco Leonardi and others friends, serving as its Editor-in-Chief.

In 1990 at Val d'Isère, he actively participated in the creation of the World Federation of Interventional and Therapeutic Neuroradiology, of which he was the first General Secretary and then President since 2007. Partisan of the necessity of preserving close connections between diagnostic and therapeutic neuroradiology, he was also a founding member of the World Federation of Neuroradiological Societies, in which he led several committees, as well as being a member of the Executive Committee. During the last few years, he dedicated a large part of his time to developing relationships between neurology, neurosurgery, and radiology within the European Union of Medical Specialists. Due to his effort, neuroradiology is now accepted as a freestanding discipline of radiology in Europe.

Intelligence cannot flourish unless it is enriched by sensi- 
tivity, and that of Pierre Lasjaunias was obvious to all who knew him. He had an esthetics of life; that is to say he held a true ethic, which directed all his actions, professional or otherwise. Finally, it is difficult to speak of Pierre without touching on what was most dear to him. Never, in all the many trips we took together, no matter how distant they were, were his heart and thoughts far from those he cherished most: his wife Pascale and their 3 daughters, Estelle, Aude, and Coline, with whom we share a most profound sadness.

International neuroradiology has lost one of its most brilliant leaders. During the memorial ceremony organized at
Bicêtre Hospital, many colleagues and friends from around the world expressed with deep emotions their respect and affection for this great master. All of us who knew Pierre Lasjaunias had the rare opportunity of encountering a human being of immense qualities, a man of incredible energy, and an extraordinary individual whom we will always continue to love and admire.

L. Picard, President World Federation of Neuroradiological Societies

DOI 10.3174/ajnr.A1342 